\title{
Maximum power tracking control of the stand-alone photovoltaic power system
}

\author{
Xiangjie Xie \& Guangqi Zhou \& Yao Chen \\ North China Electric Power University
}

Keywords: PV; Solar; panel; Maximum; Intensity; Tracking; MPPT.

\begin{abstract}
With the growing energy crisis, environmental protection becomes more and more important. People put more eyes on research and application of renewable energies. Among them, solar energy has being paid attention and has been affirmed by the whole world for its abundant amount, clean and less noise. However, low utilization rate has been one of the biggest problems plaguing scientists. Maximum Intensity Tracking and MPPT has far-reaching significance in improving power generation efficiency, lowing costs. Solar cells are key components of solar photovoltaic energy conversion technologies .Using the above two methods can effectively improve the utilization of solar cells, taking full advantage of it has great practical significance on many occasions.
\end{abstract}

\section{Introduction}

Photovoltaic Generation is a technology, which converts sunlight directly into electricity depending on photovoltaic effect above semiconductor interface. The key element of this technology is solar cells. A series of solar cells can be encapsulated to a large area of the solar cell module, which forms photovoltaic device coupled with the power controller and etc.

Whether used independently or Grid Connected, a photovoltaic system consists of an arrangement of several components, mainly including solar panels, solar inverter and controller. They are mainly composed of electronic components, not involved mechanical components.

\subsection{PV used independently}

PV used independently is a power generation that the power system is not involved in public grid-connected. And it only meets the needs of small-scale electricity which is typical to use batteries to store electricity.

\subsection{Efficiency of PV}

Solar panel is a key component of photovoltaic power generation system. Recently, the majority of modules use wafer-based crystalline silicon cells, accounted for $80 \%$ of the world solar cells market. Currently the sunlight conversion rate is around $12 \%$ 20\%, the efficiency of PV is only about $10 \%$ considering efficiency of the inverter. And it is mature in technology, the possibility of efficiency improvement and cost reduction is small. However in the thin-film solar cells market, the largest share is amorphous silicon cells. Thin film solar cell in large scale efficiency has been increased to $7 \% \sim 12 \%$. What's more, conversion efficiency of polycrystalline silicon solar cells is generally about $12 \%$ to $14 \%$.

Table. 1

\begin{tabular}{ccc}
\hline Type & Material & Efficiency \\
\hline \multirow{2}{*}{ crystalline silicon cells } & single crystal silicon & $14 \% \sim 25 \%$ \\
& & $11 \% \sim 21 \%$ \\
& polycrystalline silicon & \\
& & $8 \% \sim 13 \%$ \\
thin-film solar cells & amorphous silicon & $10 \% \sim 15 \%$ \\
& cadmium telluride & $10 \% \sim 15.5 \%$ \\
& CIGS & $20 \% \sim 40 \%$ \\
\hline
\end{tabular}


Various types of solar cells conversion efficiency are shown in Table 1.

Thus, main disadvantages of photovoltaic power generation system is its high cost and low conversion efficiency. Commercial photovoltaic power generation is lower than conventional power efficiency (traditional nuclear power 30\%, thermal power 36.8\%, new nuclear power $42 \%$ 57\%).Capacity and price cannot compete with conventional electricity. Therefore, since the internal principles and technology cannot improve the efficiency of PV, it is significant to maximize output power through external control.

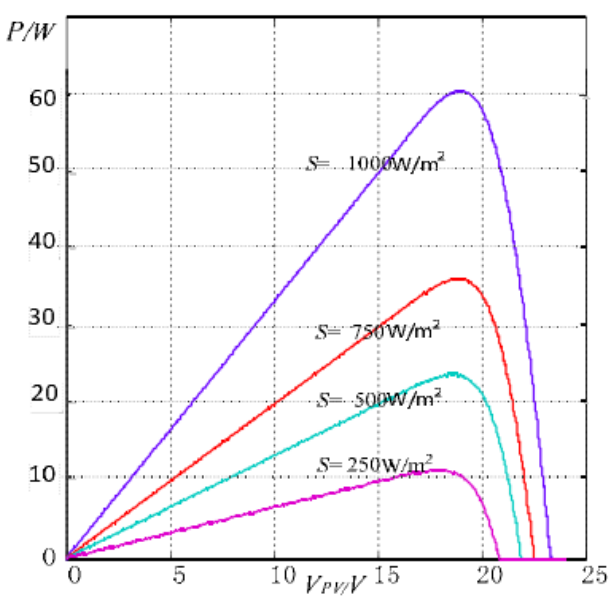

(a) P-V curve

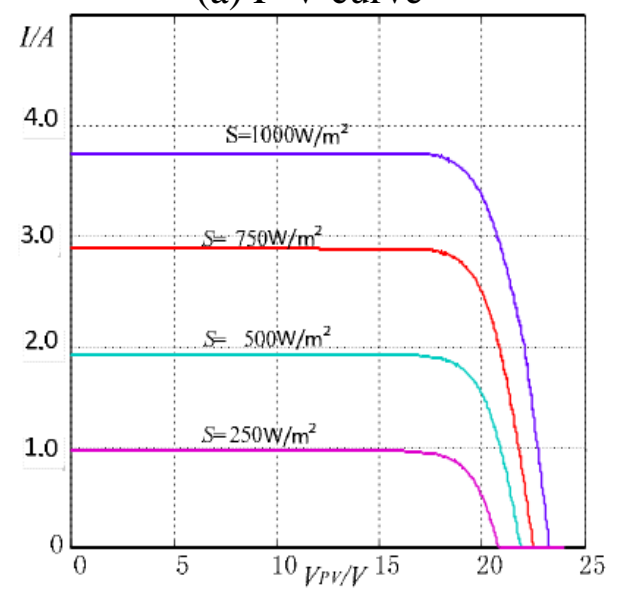

(b) I-V curve

Fig. 1 Output characteristics at different temperatures

\section{Principle Analysis}

Maximum Power Tracking combined with Maximum Intensity Tracking is different from traditional Maximum Power Point Tracking(MPPT).

\subsection{Maximum intensity tracking}

Solar panels are placed outdoors, the experiments show that is: rated output power of cells with increasing temperature will be slightly decreased. And the external environment has a great impact on temperature, so controlling the temperature has little significance to increase the output power.

When the temperature is constant, the output curve of photovoltaic cells under different sunlight intensity are shown in Figure 1.While sunlight intensity changes, the open circuit voltage is essentially the same, but short-circuit current value has great changes that it increases with light intensity enhancing so that the maximum output power also increases. Thus, light intensity is an important factor affecting the strength of the output power.

From this, the tracking direction of the strongest light intensity has a positive effect on improving the output power of the solar panel. 


\subsection{Maximum Power Point Tracking (MPPT)}

Maximum Power Point Tracking (MPPT) is a system which can output more power by regulating working state of the electrical module, and it can make DC issued by t solar panels effectively stored in the battery. So it can effectively solve domestic and industrial electricity in remote areas and tourist areas that the conventional power grid cannot cover and cause less environmental pollution. However, there are still some problems in current PV. For example, it shows the non-linear electrical behavior of the solar cell, output power is affected by light intensity, temperature and load conditions and etc. For any given set of operational conditions, cells have a single operating point where the values of the current (I) and Voltage (V) of the cell result in a maximum power output. This is known as the maximum power point (MPP).

Therefore, in order improve the overall efficiency of the system, the operating point of the PV array should be adjusted to operate at about maximum power. This process is called as maximum power point tracking (MPPT).

\section{COMPREHENSIVE Analysis}

\subsection{The maximum intensity tracking analysis}

According to the analysis of maximum power tracking, we need to make the solar panel spins with the strongest sun light. This need to know the solar altitude angle in different locations and time.

The solar altitude angle. For a place on the earth, the solar altitude angle is the angle between the ground level and the light direction of the sun. The height of the sun is an important factor of energy getting on the earth's surface. We use $h$ to represent this angle.

The general time. The solar altitude angle h changes with the local time and declination. We use $\delta$ to represent declination, use to represent latitude (north latitude for positive and south latitude for negative), use t to represent local time. We have the formula of solar altitude angle:

$\sinh =\sin \varphi \sin \delta+\cos \varphi \cos \delta \cos t$

Noon. The angle both of sunrise and sunset is 0 , while noon is max. The formula above can be simplified as:

$\sinh =\sin \varphi \sin \delta+\cos \varphi \cos \delta$

$=>\sinh =\cos (\varphi-\delta)$

Therefore, for the northern hemisphere, $h=90^{\circ}-(\varphi-\delta)$; for the south hemisphere, $h=90^{\circ}-(\delta-\varphi)$. The formula of solar altitude angle changes as:

$$
h=90^{\circ}-|\varphi-\delta|
$$

The spin of solar panel. From the definition of solar altitude angle, we know the spin angle of solar panel h is:

$\mathrm{h}=90^{\circ}-|\varphi-\delta|$

Thus we can keep panel vertical with the sun.

\subsection{Maximum Power Point Tracking}

The principle of MPPT can be explained by P-U curve of photovoltaic cells. Plus a perturbation to change the performance of the system. According to the value and direction of power output change, adjust the disturbance value and direction so that the system output can be maintained at Maximum power point under different conditions. Although the principle of MPPT appears to be very simple, in practice there are still a lot of problems, such as the judgment of work position and MPP point, step value of perturbation selection and the influence of environmental catastrophe on output performance and so on, these all need to consider on MPPT research.

In common MPPT method has two kinds: the perturbation and observation method (also called fixed step size method) and incremental conductance method.

With the rapid development of semiconductor power device, MCU and DSP, the researchers all over the world put forward some effective power tracking control method. But whether in the application of power electronic technology and in control theory, the research is on the basis of 
perturbation and observation method and incremental conductance method. The other algorithms are all improved in the two methods according to the different environment to improve work efficiency. So what kind of ways to achieve maximum power tracking also need specific analysis according to different environment.

There is no doubt, no matter what kind of method to realize the maximum power point tracking of the solar cell, it have a positive effect for improving the efficiency of power generation.

\section{Conclusion}

Whether in the theory or in practice, the maximum intensity tracking and the maximum power point tracking have an important role in improving the power of photovoltaic cells. Many applications only be the one in the control used in photovoltaic power generation system, ignoring them can be combined together to have a greater extent to improve the efficiency of power generation. Of course, further studies are still needed about the two methods. In the near future, with the continuous improvement of photovoltaic power generation, it will be more and more widely used.

\section{Reference}

[1] Cao Qianyuan, 2006. Photovoltaic generation maximum power tracking study [D]. Xi' an University of Science and Technology.

[2] Issam Houssamo, Fabrice Locment, Manuela Sechilariu, 2010. Maximum power tracking for photovoltaic power system: Development and experimental comparison of two algorithms [J]. Renewable Energy, 35: 2381-2387.

[3] Joseph R Vadus 2004. Future ocean advances for 2020 some basic needs and concepts for 2020[C]. MTS/IEEE Techno-Ocean: 1-11. Oceans.

[4] Jin Zumeng, Chen Ziwu, 1997. The generality to the earth (The Third Edition) [M]. Beijing: Higher Education Press.

[5] Luiz Fernando Lavado Villa, Damien Picault, Bertrand Raison, et al, 2012. Maximizing the power output of partially shaded photovoltaic plants through optimization of the interconnections among its modules [J].IEEE Journal of Photovoltaics, 2(2):154-163.

[6] Masoum MAS, Dehbonei H, Fuehs E F. 2002. Theoretical and experimental analyses of photomosaic systems with voltageand current-based maximum power-point tracking [J]. IEEE Transactions on Energy Conversion, 17(4): 514-522.

[7] Shen Hui, Zeng Zuqin, 2005. Solar photovoltaic power generation technology [M].

[8] Trishan Esram, Patrick L. Chapman, 2007. Comparison of Photovoltaic Array Maximum Power Point Tracking Techniques [J]. IEEE TRANSACTIONS ON ENERGY CONVERSION, 22(2): 439-448.

[9] Wang Changgui, 2003. The present state and perspectives of new energy and renewable energy[C]. The memoir of solar photovoltaic industry development forum: 82-84. 